\title{
Origin and Evolution of the Concept Stress
}

\author{
José R Ponce* \\ Doctor in Psychoanalysis, Ms. in Health Psychology, Brazil
}

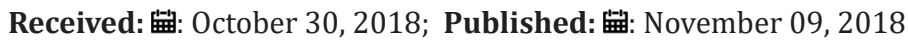

*Corresponding author: José R Ponce, Doctor in Psychoanalysis, Ms. in Health Psychology, Brazil

\begin{abstract}
It is exposed this Mini-Review where is evidenced the internal origin of the stress and its continuity, from there until to its terminal pathogenic effect of different intensity, structure and non-specificity. It can be observed into that analysis, the different conceptions about emotion and stress, and how is develop into the pattern generality-singularity-generality. Thus, the conclusion is that the relationship of emotion-stress becomes a system according the model stressor-emotional arousal-stress-dysfunction.
\end{abstract}

Keywords: Stress; Emotion; Stressor

\section{Introduction}

The Cartesian philosophies Farnell et al. [1], Pragmatic Friedrichs et al. [2], Positivist Cruickshank [3], and their influence in the emergence in the current of the Behaviorism Watrin et al. [4], they implied the focus mechanic of the separation of the body and mind in the man's study. It was braked in consequence the conception of its functional unit, driving to ignore the Hippocratic precept that the main error was to separate the mind of the body. However, the evidence of its systemic relationship has opened new perspective in these studies. In this new focus, where it is considered to the individual like system, interact the environmental, the psyche and body, but including the mediation of the nervous, endocrine and immunologic connections. Consequently, the psychic changes finish impacting in the individual's physiologic areas, and in its balance. It is implicit the archaic biological mechanism of adaptation and defense, existent in superior species and human kind, but conceptualized inside of a social mark Segerstrom [5]. In this mechanism the individual is involved in his entirety, from the cellular level until the cerebral bark, and from the conscious thing until the unconscious thing, being his end the reestablishment of the balance between the circumstances plaintiffs and the posture affective.

But if the circumstances becomes critical because of is smashed the individual's balance with their reality, by demands for which doesn't possess possibilities of an immediate and effective answer, the mechanism of adaptation-defensive is hypertrophied in detriment of the homeostasis; takes place the stress. The stress, although the term in its translation to the Castilian language is not exact, it supposes global imbalance of the body and the individual's mind. The concept appears in the XIV century in English language, being used to express hardness, tension, affliction or adversity. In the XVIII century Thomas Young defines stress like the stretching suffered by the metal due to the external pressure, loud as the force exercised on this metal, and strain like the deformation or print created by this pressure Lazarus et al. [6]. However, the concept stress, in the sciences of the health, arises properly in 1936 Seyle [7], when its pathogenic effect is evidenced in researches on the system neuroendocrine.

In the evolution of the studies around the health, the concept stress and their effects pathogenic have taken progressively wide protagonism. However, not always is approached in its relationship with the emotion. Both processes often are studied in a separate way, without being specified their interconnection. Starting from studies of Richard Lazarus, is that it is pay bigger attention to the relationship cause-effect between stress and emotion. Mainly because of the conception of Hans Seyle that the emotional arousal is the most common stressor, and in extreme grades it is evidenced as the decisive internal variable in stress source. The first thing to take into account in the relationship emotion-stress is the opposition into the emotional process. While is satisfied balanced and satisfactorily the necessity, the emotional reaction is benign. But if demands are received that surpass the possibilities of immediate and effective satisfaction, then the emotion acquires extreme intensity, as compensating the deficit of adaptation. In consequence, the imbalance in the homeostasis takes place; the stress appears Yerques/Dobson Dallman et al. [8].

In animal species, usually, the extreme emotion unchains the biological mechanism of fight defense or escape Cannon [9], and that state implies homeostatic imbalance; therefore stress. 
However, under natural conditions that reaction is ephemeral and without leaving considerable damages. It increases the defensive power, sometimes bloody, but the energy vanishes as spreads the action; its destination is to be used in the movement. In other words, the emotional and cerebral activation vanishes in the creation successive of new focuses of cortical excitement. These absorb energy in each moment, and as result takes place the cortical inhibition. In consequence, decreases the emotion, and is recovered the homeostatic balance. Stress vanishes and the animal returns to the normality Pribram et al. [10,11]. However in the human being the process follows a different course, the emotion it is less preponderant than in the animal because of the intervention of superior feelings, the conscious knowledge and rational image Padmala et al. [12]. The human emotion, contrary to the animal, is socialized in itself, although its structure physiologic is continuity of previous species. For example, the pleasure remains in the memory in a conscious way, that which doesn't happen in the animal Frederickx et al. [13].

This biological and psychological model of adaptation is translated to the man through the phylogenetic evolution, the social-conscious thing is juxtaposed to the biological thing, but it is reprocessed inside a different context. The animal possesses only behaviors fight/fly escape for his defense, while the man possesses as primordial resource the knowledge; although this cannot always respond with effectiveness to the demands of the circumstances. In the man, the imbalance created by the energy emotional surplus, which continues growing until being satisfied the necessity, acquires character pathogenic, not being this way in the animal. The multiplicity of circumstances in that the individual moves, as well as the legal, moral, social norms, individual expectations, memories, and other demands affectively intense, it supposes that the man is not always qualified to respond with precision and effectiveness. The individual, when feeling impotent, it is intensified the brain-emotional activation somehow, without the enough conversion in physical neither mental action. In consequence, this energy remainder reverts in a noxious way toward the individual, unbalancing its homeostasis, and therefore the stress arises.

Increases the difficulty in the study of the pathogenic effect of the stress due to the character no-specify of their manifestation and their consequences, the indetermination of the causal factors, and the singularity of their internal source, the arousal emotional. The damage taken place by the stress in the body-mind is manifested through the most vulnerable roads; organs, tissues and mind, in nonspecific way Lazarus et al. [6,14]. Also, the noxious consequences of the stress and their internal dynamism are not always manifested in a clear way. The relationship among the emotion, stress, homeostatic imbalance, and emergence of related dysfunctions, implies serious difficulties in its manifestation, so much theoretical as methodologically, and with enough it evidences. To it is added it that according the conception of against-shock, of Hans Seyle [14], the effect pathogenic of the stress is not always manifested during or immediately after happening the event of stress but when lapsing the time.
Therefore, if it is possible to suppress or to reduce the effect of stress efficiently, the damage taken place in the body-mind is minimum, but otherwise acquires character pathogenic Brennfleck [7]. From here comes the concept of vulnerability to the stress, the one which expressed the relationship among threshold of sensibility in the individual, given the concrete situation, and the possibility of its effective confrontation. In these pages is defined stress like the imbalance pathogenic of the body-mind, caused by the extreme brain-emotional activation, which has place like compensation and internal adjustment before the physical, psychic and social demands for which the individual doesn't possess enough immediate and effective possibilities of solution, adjustment or suppression. While emotion is the process of the psychic system, generated by elevation of the tone of operation of the encephalic fabric, like foundation of the individual mobilization before the demands affective received.

\section{Studies about the Emotion}

The records of the study of the stress are remitted to the study of the emotion, since it is their main source Lazarus et al. [6]. This relationship becomes evident to beginnings of the XX century; when they were imbricate both concepts to each other Marks et al. [16]. In the study of the emotion and their pathogenic consequences, there are a slope neurophysiologic and a properly psychological slope. Both possess their premises in the antiquity, where it was considered the emotion like confusion; the own etymological root of the term affection comes from Latin affectus, which means alteration of the soul. Inside the first thinkers that approach this psychic facet in the human the thinkers were Aristotle and Plato. Particularly Plato, in Dialogues Fedón and Carmides, contemplate the catharsis like crucial phenomenon in mental health. While Aristotle, in his Rhetoric book, bases wine, music and aphrodisiacs like means of cure of the soul. Later on, when lapsing of the time, new focuses of the emotion arise, between the XVI-XVII centuries. In that time the conception of Renato Descartes is exposed, in its Treaty of the Passions of the Soul is observed its conception of the relationship between soul and body, but in way mechanic, as separate entities to each other.

Spinoza was added to this study in its book Ethical (part III, definition 3), considering it as state that increase or diminishes the capacity to act. In the XVIII century arise the theories Sensualists, of The Mattrie, Cabanis, Bichot and Buffon in study of the emotion, as well as the Intellectualist, of Herbart, which extended until principles of the XX century and who it considered that the emotion was given by the conflict among the cognitive representations Fraisse [9]. Charles Darwin pointed out the paper utilitarian of the emotional expression [17-20]. At the end of the XIX century William James publishes the article, "What is emotion" James [21], and next to the Danish Carlos Lange, publishes its article "The emotions", to constitute the theory James-Lange Breedlove et al. [22]. This theory outlines that the visceral changes taken place as result to a given situation are perceived as emotional state. This, for James, is the effect of the organic changes as answer to critical situation. That is to say, the physiologic interference is who causes emotion, even 
the escape reaction, determined by the feelings of fear and terror, finds its cause in the corporal movement that responds to threat or aggression.

In other words, the terror doesn't cause the impulse of escape, but on the contrary, the proprioceptive and interoceptive sensations, originated in the corporal movement, are who produce the terror. Also explains this author how in the superior feelings the mechanism is the same one but the organic change is not easily conscious. Nevertheless its theory, as the one pointed out, is referred to the violent emotions. This theory caused an avalanche of experimental works directed to prove or to refute this conception. They were made numerous objections and against-objections, among these that of Walter Cannon who being based on physiologic studies in cats Cannon [23]. Pribram summarizes in five points the objections of Walter Cannon to James' theory Vynken et al. [11]:

a. The separation of the viscera of the system nervous power station doesn't modify emotional behavior.

b. The same visceral changes low states emotional, but also low non-emotional states are presented.

c. The viscera are relatively insensitive structures.

d. The visceral changes are too slow to be source of emotion.

e. The artificial induction of visceral changes, typical of intense emotion, it doesn't originate this state.

Also Sherrington Vynken et al. [11], in their studies with dogs, it follows the same line of Cannon, and with it refuted it to James. It cut, in a surgical operation at five of them, the connection between vague nerve and spinal cord, preventing that the effect of visceral alteration arrived to the bark. It faced the animals to stressful situations, and in the entire cases one could observe manifestations of emotion. Walter Cannon, among XIX and XX centuries, studied the relationship among the autonomous nervous system, the subbark and the emotion; especially structures of the thalamus and hypothalamus. If William James outlined the visceral or outlying theory of the emotions, Cannon it exposed the sub-cortical theory like the central axis of the emotion. It also exposed their concept of Emergency Reaction, where the defensive behaviors of the fight or fly like resultant of the emotional shock are manifested in the animal Cannon [25]. Cannon, in the perception of emotive situation coincided with James, but their conception was that the generator of this state was a device in the thalamus, which induced organic changes. With that settled down it the theory Cannon-Bard Breedlove et al. [22]. Those approaches of Cannon contributed precedent to the study of the stress, although it was not object of their study properly, neither he took sufficiently into account the psychological mediator.

Wilhelm Wundt exposed the Three-dimensional theory of feelings, and although this it is not defined with clarity in its difference with the emotion, it considered that these states are inside a three-dimensional space constituted for: tensionrelaxation, excitement-calm, pleasure-displeasure, where emotion was complex combinations of these dimensions. Wundt carries out experiments in its laboratory, and it contributes by means of these to a multidimensional conception of these states, and to the current concept of the emotion and its internal dynamics Nicolás et al. $[14,26]$. Later on arises the theory of Pavlov, which consider the origin of the emotion in the dynamic stereotypes Pavlov. Later came the theory Papez-Mc Lean, which located the center of the emotional reaction in the system limbic Pribam et al. [11,27$29,43,45,53]$. To this theory it continued him that of Arnold and Lindsley, which outlined the origin of the emotion in the cerebral activation, but locating their center in the Reticular Formation of the Encephalic Trunk Vynken et al. [11,29].

This theory seemed to support that of Cannon-Bard and to James-Lange as physiologic origin of the emotion. However, it was also overcome by another theory, that of Karl Pribram who ends up demonstrating that when being stimulated diverse areas of the cortex visceral, takes place answer without emotion, and at the same time areas of the brain unaware to the limbic system are involved. Pribram starts from the self-regulation of the emotional reaction, establishing bases of a theory of cybernetic character that completed the approach of the cerebral activation. This author establishes the pattern TOTE, Test-Operate-test-Exit, where it considers that the emotion is produced by disorganization of the neural systems Priban et al. [30]. Contemporary with these theories, Duffy considers the emotion an unique dimension of excitement, that is to say, a continuum of activation levels from the dream until the fury [15] Lindquist et al. [31]. This theory points to the activation in the brain, and it considers essential generator from the emotion to the reticular Formation of the encephalic trunk.

Leontiev [32], in the second half of the XX century, it considers the emotion like product of the relationship between necessity and satisfaction. Schachter studies it as physiologic activity with cognitive guide, and Rezenszein, following Sachter, conform a unique theory. Lassen, Ingvar and Skinhoj they expose, on the base of experimental studies with cerebral images that the emotion was the psychic process of more correlation with cortical functions. Plutchik [33] it develops the theory Psycho-evolutionist. This, being based on the Darwinist theory, it focuses the emotion with defensive character again, and it contemplates the knowledge like factor evaluative in this reaction. It also considers that the emotion is expressed in a complex combination of feelings until adopting forms given around an excitement axis. At this moment the emotion is focused in an integral way. The effect of activation physiologic and emotional invades successive nervous areas in a recruitment process, and impacts, by means of nervous innervation, on the organism and the psyche until the cellular level.

Even it can be defined their differences with the feeling, which is the psychic process that defines the affective sense of the object in function of the related motivation. If the emotion is activator of the body-mind, the feeling it defines the affective sense of the object Jaremka et al. [34]. The study of the emotion has been object of multiple polemics happened inside the scientific consensus. In the first place the definition of if it is psychological or physiologic process Vinken et al. [11]. In second place is discussed if it disorders or not 
the behavior, including the synthesis of both positions starting from the law of Yerques-Dobson Fraisse [35]. In third place, is discussed the relationship of the emotion with the superior feelings and the psycho-biological affective reactions Dzhidarian [36]. However, all scientific groups coincides that the emotion possesses function of adaptation, especially defensive, through the evolution Plutchik [37]. These approaches, in any way, suppose existence of channels of emotional transmission through somatic concatenations, that which allows centralization of the individual's integral control and relationship activity. This way, although psychic, the emotion is also biological.

\section{Evolution of the Stress Concept}

The premises of the studies of the stress are in the empiric observation, from the humanity's early date, of the pathogenic effect that produces the emotion in their extreme level about the health of the human being Diaz. Nevertheless, in these studies there is not an integral focus, some theories highlight physical aspects, others remark their psychic condition, and others focused its adaptive function. For Claude Bernard the stress was an adaptive response to an external stimulus, trying the internal conditions to recover balance, if the answer is insufficient appears the illness Lazarus et al. [38]. Later on Walter Cannon, in spite of not focusing the stress sufficiently, considers this state as the stimulus that causes the alarm reaction, and it exposes its homeostasis, opposite to the stress. It defines the homeostasis like: The coordinated process that maintains most of the physiologic constants of the organism cited by Seyle. These way different authors surround this phenomenon until Hans Selye opens the road for a new conception.

This author carries out his investigations around the endocrine functions that takes place because of the external pressures to which it is subjected the individual. In 1946 Seyle it defines stress like the state of resulting tension of a noxious, abrupt or continuous, action for the organism. Later on it redefines it as deviation of the normal physiologic state or state of rest that affects to extensive parts of the organism (Seyle 1954). In 1971 he defines it as: A non-specific answer of the organism before any demand made on him. It is a stereotyped pattern, phylogenetically archaic, that prepares to the organism for the fight or the escape. These answers of the Stone Age are caused by many situations of the modern life, when the physical activity is impossible or completely unacceptable (Cited for Alvarez, 1989). In 1975 Seyle considers to the stress like the non-specific answer from an organism to any unpleasant requirement or not Lazarus et al. [38]. Hans Seyle establishes its theory around the call General Syndrome of Adaptation, where considers the existence of diverse endocrine process which produce the internal modifications when not being channeled in the activity. This author considers this syndrome like it adds of reactions due to the lingering exhibition to the stimulus Seyle [14].

The essential aspects of the theory of Seyle on the stress are the following ones:

a. It is a non-specific answer from the organism to the imposed demands. b. Stressor is all noxious agents for the homeostatic balance of the organism.

c. Any stimulus can be stressor when causes answer nonspecific of stress.

Objections to Hans' theory Seyle:

a. It doesn't end up clarifying thoroughly on what it consisted the energy of adaptation.

b. It didn't focus the central nervous system sufficiently, and neither the psyche. Nevertheless, at the end of their life it exposed that: ... the emotional arousal is the cause more common of stress Mentioned for Lazarus et al. [38].

c. The theory doesn't establish the profile so that a stimulus is considered stressor.

The general Syndrome of adaptation is focused in a biological way, but it connects with psychological works of the stress carried out by other authors, reason why in its study diverse disciplines and focuses have converged Steinberg et al. [39]. Among these, in the Institute of the stress of Karolinska, in Sweden, impulse was printed to the investigation of labor stress in authors like Lenart Levi, Töres Theorell, Robert Karasek from the decade of the 1970 Santavirta et al. [40,41]. Another author, Wolf, considered stress like disturbing experiences of the past Lazarus et al. [38]. Elliot on the other hand, considered stress like cause of an emotional or physiologic effort, resultant of a perceived fight, or the imbalance among what the person wants that happens and the reality of the environment. This sustains their conception in vast experience in the cardiovascular treatment. Another author is Steinberg et al. [39] who focus the stress as based on the input and the output of a system .

Lazarus et al. [38] outline the stress as a result of different variables and processes, and they define it as: The particular relationship among the individual and the environment that it is evaluated by this as threatening or overflowing of their resources and that it puts in danger their well-being. Lazarus et al. [38] considers cognitive evaluation as the determinant of the sense stressful of an event, that which is regulated in each individual through by their Beliefs, that is to say preformed cognitive configurations, and by Commitments, that which supposes implications affective. The evaluation possesses two stages, the primary one, where he/she is defined the stimulus as it is Outstanding, Benign-positive, or Stressful, and the Secondary, where possibilities are evaluated of confronting the stressor. On the other hand, consider the confrontation like processes through which the individual manages the demands that he evaluates stressful, and the emotion that generates it. According to Brennfleck [42], the confrontation capacity is tied on one hand, to the sense of the stressor and possibility of to reduce or to suppress its effect, and for the possibility of its prediction, duration, distance and frequency to the exhibition of the stressor.

This author also considers that according to the form in that the stress is confronted it can become a new stressor, because when 
being suffered the event stressful, the individual can continue having presented the fact, what implies an additional effect. Meichenbaum [43] it considers that the emotional sensibility is determined by the interpretation that is made of the object, starting from it the magnitude of the stressor, occurrence probability, and resources for the confrontation, they regulate the effect of stress. Ader marks an inflection point in the study from the stress when considering that it is not a monolithic concept, but of modality and varied intensity. For this author, different factors generate stress, and it is translated in multiple effects Friedman et al. [44]. While Kendall-Tackett [45] considers that the stress happens when the demands exceed the capacity of adaptation or ability for its confrontation. In general, they have been defined three fundamental focuses for the study of the stress. The first one, centered in the event stressful, the second in the internal changes in the health and the body, included the effect pathogenic, and the third focused in the interactive relationship between circumstances stressful and the individual's vulnerability Marks et. al. [46-55].

\section{Conclusion}

In summary, it is evidenced that the stress constitutes an imbalance pathogenic and systemic, caused in the external by multiplicity of factors plaintiffs to the individual, to those which is impotent to confront in an immediate and effective way. Internally, as response to stressors, is stimulated the archaic mechanism of adaptation and defense, but in hypertrophied way. In this mechanism, the activation acquires high grade of intensity, and the arousal emotional end takes place in compensatory response to the impotence before these demands. So, the arousal emotional constitutes the singular mechanism to produce stress, and that state is manifested through of the physiology and psychology of the individual in a non-specific way. In conclusion, the stress is open system, with stochastic character in its external causes, and with a singular internal source, the arousal emotional. Chord to it, the pattern generality-singularity-generality, inside which the stress is framed, is summed up in: stressor-emotional arousal-stressdysfunction.

\section{References}

1. Farnell B, Varela CR (2008) The Second Somatic Revolution. Journal for the Theory of Social Behaviour 38(3): 0021-8308.

2. Friedrichs J, Kratochwil F (2009) On Acting and Knowing: How Pragmatism Can Advance International Relations Research and Methodology. International Organization 63(4): 701-31.

3. Cruickshank J (2012) Positioning positivism, critical realism and social constructionism in the health sciences: a philosophical orientation. Nursing Inquiry 19(1): 71-82.

4. Watrin JP, Darwich R (2012) On Behaviorism in the Cognitive Revolution: Myth and Reactions. Review of General Psychology 16(3): 269-282.

5. Segerstrom SC (2010) Resources, Stress, and Immunity: An Ecological Perspective on Human Psychoneuroimmunology. Annals of Behavioral Medicine 40(1): 114-125.

6. Lazarus R, Folkman S (1984) Stress, Appraisal, and Coping. Springer Publishing Company: New York, USA.

7. Seyle H (1936) A syndrome produced by diverse nocuous agents. Nature 138: 32 .
8. Dallman MF, Hellhammer D (2011) Regulation of the HypothalamoPituitary-Adrenal Axis, Chronic Stress, and Energy: The Role of Brain Networks. In RJ Contrada, A Baum (Eds.). The handbook of stress science: Biology, psychology, and health (p. 394). Springer Publishing Company, New York, NY, USA.

9. Eliot RS (1987) Stress and Cardiovascular Disease: Mechanisms and Measurement. Annals of Clinical Research 19(2): 88-95.

10. Pribram KH (1998) Thoughts on the Meaning of Brain Electrical Activity. International Journal of Psychology 33(3): 213-225.

11. Vinken FJ, Bruyn G W (1980) Neurofisiología contemporánea. Tomo III. Editorial Científico-Técnica, Cuba.

12. Padmala S, Kenzer A, Bauer A, Pessoa L (2012) Interactions Between Cognition and Emotion During Response Inhibition. Emotion 12(1): 192-197.

13. Frederickx S, Verduyn P, Koval P, Bransi K, Brunner B, et al. (2013) The Relationship Between Arousal and the Remembered Duration of Positive Events. Applied Cognitive Psychology 27(4): 493-496.

14. Seyle H (1954) Stress. Sufrimiento Editorial Científico-Médica, España.

15. Marks DF, Murray M, Evans B, Estacio EV (2011) Health Psychology: Theory, Research, and Practice, ( $3^{\text {rd }}$ Edn.). Sage, London.

16. Darwin Ch (1903) La expresión de las emociones en los animales y en el hombre, Valencia, España: Editorial Arte y literatura. Traducido por Eusebio Heres.

17. Berthoz S, Blair RJR, Le Clec'h GJ, Martinot L (2002) Emotions: From neuropsychology to functional imaging. International Journal of Psychology 37(4): 193-203.

18. Ciompi L (2003) Reflections on the role of Emotions in Consciousness and Subjectivity, from the Perspective of Affect-logic. Consciousness \& Emotion 4(2): 181-196.

19. Fraisse P (1965) Las emociones. En: Paul Fraisse \& Jean Piaget. Tratado de Psicología Experimental. Tomo V. Facultad de Psicología de la Universidad de La Habana.

20. James W (1884) What is an emotion? Mind 9(34): 188-205.

21. Breedlove SM, Watson NV, Rosenzweig MR (2010) Biological psychology: An introduction to behavioral, cognitive, and clinical neuroscience. $\left(6^{\text {th }}\right.$ Edn.). Sinauer Associates, Inc. Publishers, Sunderland, MA, US.

22. Cannon W (1927) The James-Lange theory of emotion: a critical examination and an alternative theory. American Journal of Psychology 39(1): 106-124.

23. Cannon W (1932) The Wisdom of the Body. Norton WW and Nueva C, New York, US

24. Blumenthal AL (1975) A Reappraisal of Wilhem Wundt. In: Evolving perspectives on the history of psychology. Pickren, Wade E, Dewsbury, Donald A (Eds.). American Psychological Association, Washington, DC, USA, p. 65-78.

25. Papez JW (1937) A proposed mechanism of emotion. Archives of Neurology and Psychiatry 38(4): 725-743.

26. Dalgleish T (2004) The emotional brain. Nature Reviews Neuroscience 5: 583-589.

27. Reisenzein R (2006) Arnold's theory of emotion in historical perspective. Cognition and Emotion 20 (7): 920-951.

28. Pribam KH, Melges FT (1980) Bases fisiológicas de la emoción. En: Neurofisiología contemporánea. Tomo 3. Editorial Científico-Técnica, Cuba.

29. Duffy E (1962) Activation and Behavior, Wiley, New York, USA.

30. Lindquist KA, Siegel EH, Quigley KS, Feldman Barrett L (2013) The Hundred-Year Emotion War: Are Emotions Natural Kinds or 
Psychological Constructions? Comment on Lench, Flores, and Bench. Psychological Bulletin 139(1): 255-263

31. Leontiev AN (1982) Actividad, conciencia y personalidad. Editorial Pueblo y Educación, Cuba.

32. Jaremka LM, Gabriel Sh, Carvallo M (2011) What Makes Us Feel the Best Also Makes Us Feel the Worst: The Emotional Impact of Independent and Interdependent Experiences. Self and Identity 10(1): 44-63.

33. Dzhidarian IA (1980) Acerca del lugar que ocupan las necesidades, las emociones y los sentimientos en la motivación de la personalidad. En: Problemas teóricos de la psicología de la personalidad. Editorial Orbe, Cuba.

34. Plutchik R (1991) Emotions and Evolution. International Review of Studies on Emotion. Strongman KT (Eds.). John Wiley and Sons Ltd, USA, p. 1.

35. Steimberg A, Ritzman R (1990) A Living Systems Approach to Understanding the Concept of Stress. Behavioral Science 35(2): 138146.

36. Santavirta N, Solovieva S, Theorell T (2007) The association between job strain and emotional exhaustion in a cohort of 1,028 Finnish teachers. British Journal of Educational Psychology 77(1): 213-228.

37. Kivimäki M, Nyberg ST, Fransson EI, Heikkilä K, Alfredsson L et al. (2013) Associations of job strain and lifestyle risk factors with risk of coronary artery disease: a meta-analysis of individual participant data. Canadian Medical Association or its licensors CMAJ 185(9): 763-769.

38. Brennfleck Sh J (2002) Stress Related Disorders. Omnigraphics, Detroit USA.

39. Meichembaum D (1988) Manual de Inoculación de estrés. Ediciones Roca SA, Madrid, Spain.

40. Friedman H, Klein TW, Friedman AL (1995) Psychoneuroimmunology, Stress and Infection. FL: CRC Press, Boca Raton, US.

41. Kendall Tackett K (2010) The psychoneuroimmunology of chronic disease: Exploring the links between inflammation, stress and illness. Washington DC American Psychological Association.

42. Alvarez González MA (1989) Estrés. Un enfoque psiconeuroendocrino. Editorial Científico-técnica: Cuba.

\section{ISSN: 2574-1241}

DOI: $10.26717 /$ BJSTR.2018.10.002018

José R Ponce. Biomed J Sci \& Tech Res

This work is licensed under Creative

Commons Attribution 4.0 License

Submission Link: https://biomedres.us/submit-manuscript.php
43. Contrada RJ, Baum A (2011) The handbook of stress science: Biology, psychology, and health. Springer Publishing Company, New York, USA ISBN: 978-0-8261-1471-6.

44. Díaz JL (1990) La Nueva faz de la emoción. Revista Salud Mental 13(4): 13.

45. Gerin W (2011) Acute Stress Responses in the Psychophysiological Laboratory. In: RJ Contrada, A Baum (Eds.). The handbook of stress science: Biology, psychology, and health, New York, NY: Springer Publishing Company pp. 345-357.

46. Gutman DA, Nemeroff CB (2011) Stress and depression. In Contrada RJ, Baum A (Eds.). The handbook of stress science: Biology, psychology, and health, New York, NY: Springer Publishing Company pp. 345-357.

47. Kendall Tackett K (2009) Psychological Trauma and Physical Health: A Psychoneuroimmunology Approach to Etiology of Negative Health Effects and Possible Interventions. Psychological Trauma: Theory, Research, Practice, and Policy 1(1): 35-48.

48. Leontiev AN (1966) Las necesidades, los motivos y la consciencia. Trabajo presentado al XVIII Congreso mundial de psicología: Moscú.

49. Luria AR (1982) Cerebro en acción. Editorial Pueblo y Educación, Cuba.

50. Magoun HW (1964) El cerebro despierto. Editorial La Prensa médica mejicana: México.

51. Meichenbaum D (1993) Changing Conceptions of Cognitive Behavior Modification: Retrospect and Prospect. Journal of Consulting and Clinical Psychology 61(2): 202-204.

52. Meichenbaum D (1996) Mixed Anxiety and Depression, A CognitiveBehavioral Approach, A Viewer's Manual. Newbridge Professional Programs: New York, USA.

53. Meichenbaum D (2005) 35 Years of Working with Suicidal Patients: Lessons Learned. Canadian Psychology/Psychologie canadienne 46(2): 64-72.

54. Nicolas S, Ferrand L (1999) Wundt's Laboratory at Leipzig in 1891. History of Psychology 2(3): 194-203.

55. Yerkes RM, Dodson JD (1908) The Relation of Strength of Stimulus to Rapidity of Habit-Formation. Journal of Comparative Neurology and Psychology p. 18.

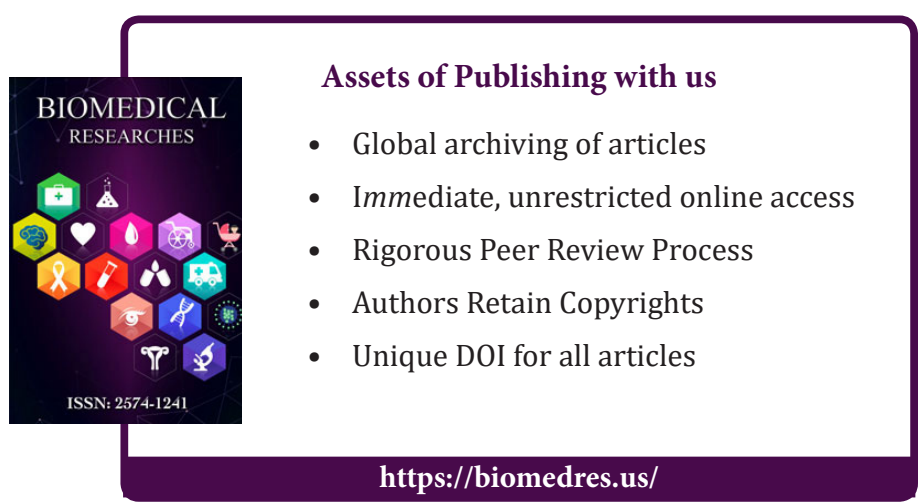

